\title{
Assessment of nutritional knowledge of patients with pancreatitis
}

\author{
Małgorzata Włochal', Ewelina Swora-Cwynar', Jacek Karczewski², Marian Grzymisławski ${ }^{1}$ \\ 'Department of Internal Diseases, Metabolism, and Nutrition, Poznan University of Medical Sciences, Poznan, Poland \\ ${ }^{2}$ Chair of Biology and Environmental Protection, Laboratory of Transplantation Immunology, Poznan University \\ of Medical Sciences, Poznan, Poland
}

Prz Gastroenterol 2015; 10 (4): 229-233

DOI: $10.5114 /$ pg.2015.52402

Key words: acute pancreatitis, chronic pancreatitis, dietary recommendation.

Address for correspondence: Ewelina Swora-Cwynar MD, PhD, Department of Internal Diseases, Metabolism, and Nutrition, Poznan University of Medical Sciences, 49 Przybyszewskiego St, 60-550 Poznan, Poland, phone: +48 61869 13 14, fax: +48 618691314 , e-mail: eswora@ump.edu.pl

\begin{abstract}
Introduction: Proper nourishment is one of the basic elements in the treatment of patients with both acute and chronic pancreatitis. Following acute pancreatitis, the essential element of nutritional treatment is dietary education. The dietary approach is used not only for treatment, but also for prevention of reoccurrence of the condition.

Aim: To evaluate nutritional knowledge of patients with acute and chronic pancreatitis.

Material and methods: The selected group consisted of 36 patients, 19 females and 17 males, suffering from acute or chronic pancreatitis. Participation in our survey was anonymous and voluntary. The study population was divided into two groups: 12 patients with acute pancreatitis ( 5 males and 7 females) and 24 patients with chronic pancreatitis ( 12 males and 12 females). The median age of patients was $42.4 \pm 14$ years (range: $20-76$ years). The duration of illness among the study population was varied. The biggest group of $16(44.4 \%)$ patients suffered from pancreatitis for more than 5 years, 8 (22.2\%) patients had pancreatitis diagnosed $1-2$ years previously, only $3(8.3 \%)$ subjects suffered from pancreatitis for shorter than half a year. To analyse patients' nutritional knowledge an authorial questionnaire was used that contained 17 closed questions and open-type questions were used three times.

Results: Most (97\%) subjects with acute and chronic pancreatitis adhered to the diet to various degrees, but almost $50 \%$ of people up to 35 years of age declared that they didn't respect the diet, or that they followed only a few recommendations. Despite each interviewer admitted to follow dietary recommendations for pancreatitis, $11.1 \%$ of patients could not indicate any of them. Most patients knew that their diet should contain a low amount of fat (61\% of patients). Awareness of alcohol abstinence was confirmed in $44.4 \%$ of subjects. One third (33.3\%) of patients knew that fried food should be avoided. Only a few patients were aware that smoking, spicy food, and strong coffee should be excluded from their diet. About $80 \%$ of the surveyed patients evaluated their level of nutritional knowledge as good or very good. Only $20 \%$ of the study population admitted their dietary knowledge was unsatisfactory, and most of these were woman (86\%).

Conclusions: The results of the present study demonstrate that dietary knowledge among patients suffering from acute and chronic pancreatitis is insufficient. Although patients have theoretical knowledge about nutritional management, they have problems implementing the diet on a daily basis. It is necessary to pay more attention to nutritional education for patients suffering from pancreatitis.
\end{abstract}

\section{Introduction}

Chronic pancreatitis is the most commonly recognised disorder of the pancreas. The first case of this disease was described by Reginal Huber Fitz more than 200 years ago [1]. Ever since then, the number of the diagnosed cases has steadily increased. The incidence rate for acute pancreatitis (AP) in Europe ranges from 20-30 cases per 100,000 people per year and for chronic pancreatitis 6-24 cases per 100,000 people per year [2]. The most frequent aetiological factors of the pancreatitis is cholelithiasis and alcohol consumption [3].

Adequate nutrition is one of the basic elements in the treatment of patients suffering from acute or chronic pancreatitis [4]. During reconvalescence, patients should be advised to adhere strictly to an individual low-saturated fat diet, with fibre restriction [5, 
6]. Total daily energy requirement should be divided into five smaller, more frequent meals. Boiling, steaming, or roasting in parchment or aluminium foil are recommended methods for food preparation. In addition, patients who are following a dietary plan for pancreatitis must avoid barbequing or deep-frying. In order to reduce dietary fibre content, it is necessary to replace wholegrain products with semolina or small pasta, and to avoid raw fruit and vegetables in the diet. Moreover, brassica and leguminous vegetables must be eliminated from the patients' menu, because they can cause flatulence. Patients should choose a low-fat products like: milk with up to $2 \%$ fat, low-fat meat, and cold cuts (poultry, turkey, veal). When it comes to preparation of soups and sauces, patients with pancreatitis should avoid roux and strong bullion. Certain types of food should be strictly excluded from these patients menu, including alcoholic beverages, coffee, chilli peppers, raw garlic and onions, all fat-full sweets, pastries, and ice cream. The spicy species may be replaced by mild herbs: cinnamon, vanilla, marjoram, thyme, basil, dill leaves [2]. An important aspect of the treatment of patients with chronic pancreatitis is also an adequate supply of pancreatic enzymes and vitamins $B, A, D, E$, and $K$ and folic acid supplementation [7, 8]. The nutritional therapy should include also nutrients with confirmed regulatory effects on the immune system like: saturated amino acids (arginine), unsaturated amino acids (glutamine, glycine), sulphur amino acids, nucleotides, polyunsaturated fatty acids $(\omega-3, \omega-6)$, antioxidants (vitamin C, vitamin $E, \beta$-carotene), and trace elements (selenium, copper, zinc, iron) [9].

The essential element of nutritional treatment following AP is nutritional education of patients. The dietary approach is used not only for treatment, but also for prevention of reoccurrence of the condition.

\section{Aim}

The aim of this research was to assess nutritional knowledge, both theoretical and practical, among patients suffering from acute and chronic pancreatitis.

\section{Material and methods}

The study was conducted between September 2010 and June 2011 in the Department of Internal Diseases, Metabolism, and Nutrition of Heliodor Święcicki University Hospital in Poznan, Poland. The selected group consisted of 36 patients, 19 females and 17 males, suffering from acute or chronic pancreatitis. The study population was divided into two groups: 12 patients with AP ( 5 males and 7 females) and 24 patients with chronic pancreatitis (12 males and 12 females). The median age of patients was $42.4 \pm 14$ years (range: $20-76$ years).
The duration of illness among the study population varied. The biggest group, 16 (44.4\%) patients, had suffered from pancreatitis for more than 5 years, 8 (22.2\%) patients had had pancreatitis diagnosed 1-2 years ago, and only 3 (8.3\%) subjects had suffered from pancreatitis for shorter than half a year.

The selection of patients with pancreatitis was based on main and additional diagnoses in order to exclude the influence of concomitant illness on the study results. Among the selected patients with chronic pancreatitis, 6 suffered from diabetes, 3 patients had underactive thyroid, and 1 had celiac disease.

To analyse the patients' nutritional knowledge, an authorial questionnaire was used. Participation in our survey was anonymous and voluntary. Each patient consented to participation in the study. The questionnaire contained 17 closed questions and certification. Opentype questions were used three times.

\section{Statistical analysis}

Results were statistically analysed using Microsoft Excel and PQStat 1.2.6. software, and the statistical functions used involved arithmetical average and standard deviation. Differences between variables were estimated by Pearson's correlation coefficient. Differences were considered statistically significant at $p \leq 0.05$.

\section{Results and discussion}

\section{Self-assessment of nutritional knowledge among patients with pancreatitis}

The nutritional knowledge of patients with acute and chronic pancreatitis was assessed by a questionnaire. Despite each interviewer admitting to follow dietary recommendations for pancreatitis, only $11.1 \%$ of patients could indicate any of them. Most patients knew that their diet should contain a low amount of fat ( $61 \%$ of patients). Awareness of alcohol abstinence was confirmed in $44.4 \%$ of subjects. One third (33.3\%) of patients knew that fried food should be avoided. Only a few patients were aware that smoking, spicy food, and strong coffee should be excluded from their diet. Haritha and Wilcox showed that $56 \%$ of patients were aware of the relationship between smoking and chronic pancreatitis, and $72 \%$ were aware of alcohol and pancreatitis [10].

About $80 \%$ of the surveyed patients evaluated their level of nutritional knowledge as good or very good. Only $20 \%$ of the study population admitted their dietary knowledge was unsatisfactory, and most of these were woman (86\%). A very strong link between negative evaluation of own nutritional knowledge and the duration of illness (less than 6 months) was detected $\left(r_{x y}=0.63 ; p \leq 0.001\right)$. This fact may suggest that the level of dietary knowledge stays in proportion to the disease 
duration. Patients who declared negative self-assessment of nutritional knowledge also admitted that their knowledge about metabolic disorders resulting from pancreatitis was unsatisfactory $\left(r_{x y}=0.75 ; p \leq 0.001\right)$. There was no statistically significant correlation between declared and real levels of nutritional knowledge.

\section{Informational source of dietary knowledge}

A lot of different sources of information are used by patients searching for nutritional advice. Most (26\%) subjects declared that theyobtained dietary advice from doctors, nurses, or dieticians. Nearly $53 \%$ of the interviewers thought that recommendations from doctors/ nurses/dieticians are the most valuable. This indicates a high level of trust in medical health care employers. It was particularly observed in the group of the elderly patients, who declared that they fully understood doctors' dietary recommendations. Negative correlation was detected between the age of respondents and the choice the electronic sources of information $\left(r_{x y}=-0.4\right.$; $p \leq 0.02$ for online articles and $r_{x y}=-0.35 ; p \leq 0.05$ for Internet forums). All interviewed patients declared that they had searched for information about diet and disease (Figure 1).

Although the dietary instructions received from health care employers were general, most interviewees (55.6\%) admitted that they understood them correctly. The reason for this process was not estimated in this study; it could be a topic for further research.

\section{Adherence to nutritional recommendations}

Most subjects (97\%) with acute or chronic pancreatitis declared that they adhered to the diet; however,

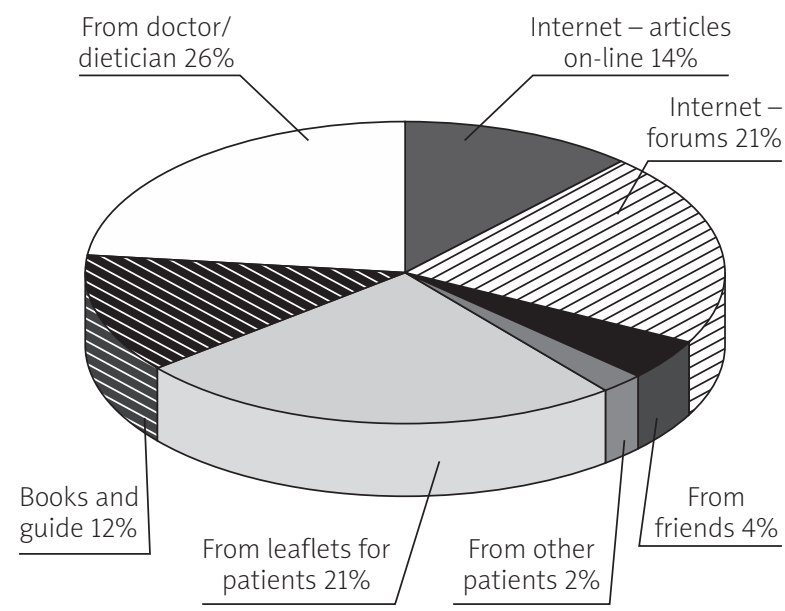

Figure 1. Sources of nutritional information the study demonstrated that the elderly patients were more consistent with their dietary choices.

There is a positive correlation between the subject's age and adherence to the diet $\left(r_{x y}=0.38 ; p \leq 0.05\right)$. The main reasons for difficulties with adherence to nutritional management in everyday life in the group of older patients (55-76 years old) were financial and sociological problems (dependence on careers).

Almost $80 \%$ of the study population between 20 35 years of age admitted that they followed the diet only partially. Most of them explained that they had no chance to follow the diet because of lack of time for healthy food preparation and regular meals. Furthermore, young people admitted to a lack of strong motivation to maintain a good nutritional approach. Additionally, the results show that patients who demonstrated broad knowledge about pancreatitis were able to follow dietary recommendations to a greater extent $\left(r_{x y}=0.47\right.$; $p \leq 0.05$ ) (Figure 2).

Most of the study population (63.9\%) evaluated that it is possible to follow nutritional recommendations on an every day basis. The remaining 30\% of patients declared that it was difficult to adhere to the diet. Based on the surveys, it can be concluded that most of those people did not search for information or did not make use of dietary consultations for over 2 years of the disease duration $\left(r_{x y}=0.34 ; p \leq 0.05\right)$.

Our results demonstrate a correlation between duration of pancreatitis and information update frequency. All of the patients suffering from pancreatitis for less than for 6 months had been looking for dietary advice within 2 months prior to survey $\left(r_{x y}=0.4\right.$; $p \leq 0.05)$. These patients admitted that they were unsatisfied with the help that they had received from doctors/nurses/dieticians because it was incomplete

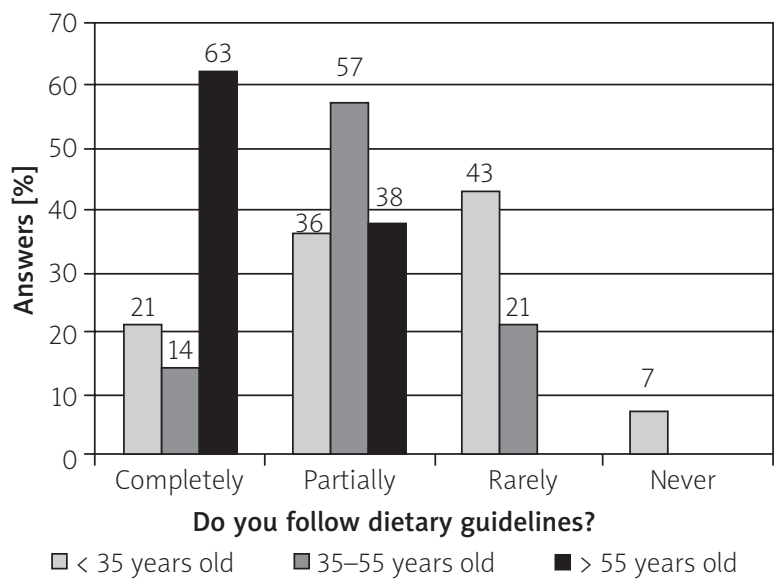

Figure 2. Relation between adherence to the diet and patients' age 


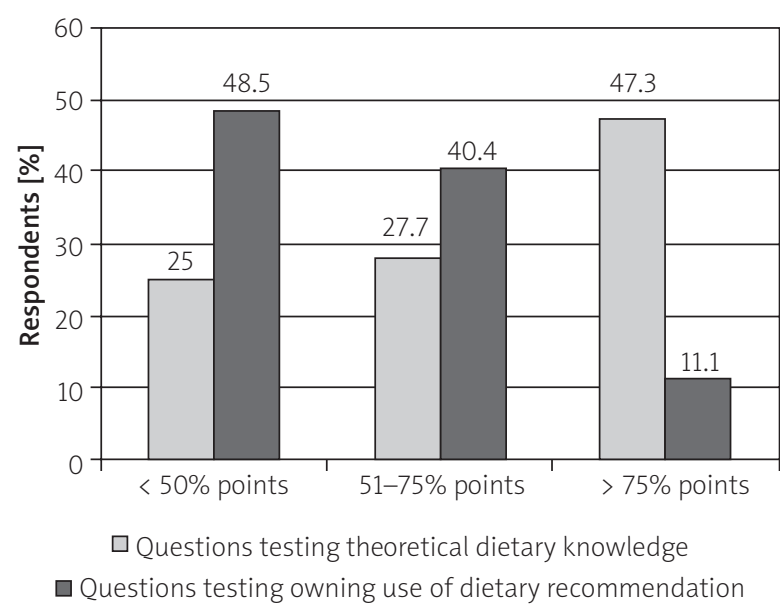

Figure 3. Theoretical and practical dietary knowledge among patients with pancreatitis

or unclear. Moreover, they thought that the dietary plan presented by healthcare employers was difficult to follow in everyday life $\left(r_{x y}=0.4 ; p \leq 0.05\right)$. People with disease diagnosed 5 years ago did not have the need for frequent updates on their dietary knowledge. Most of them looked for advice 7 to 12 months prior to the survey $\left(r_{x y}=0.46 ; p \leq 0.01\right)$. In addition, almost half of those people declared that for over 2 years they did not consult a specialist in order to obtain dietary advice $\left(r_{x y}=0.4 ; p \leq 0.05\right)$. The dietary and disease-related knowledge of patients suffering from pancreatitis can be estimated as unsatisfactory. The results from this research are similar to the conclusions published by Majewski' et al. [11], who concluded that the nutritional knowledge of patients with gastroenterological problems was superficial.

The interview patients were asked about the presence of accompanying metabolic disorders, secondary to pancreatitis. Every third patient reported problems with hyperlipidaemia. One fifth (20\%) of subjects were aware of the possibility of vitamin A, D, E, and $\mathrm{K}$ deficiency. Only 3 (8.3\%) patients understood the risks of diabetes because of insulin deficiency. Almost $25 \%$ of the study population did not know what alimentary consequences may appear in the course of pancreatitis.

During our study we asked subjects to choose which, from 17 available sentences on recommended diet, were correct or false. On average, 12 points were gained in this task. Almost $60 \%$ of patients could correctly answer $50 \%$ of questions, and $40 \%$ subjects answered $80 \%$ of questions correctly.

Although most patients required theoretical dietary knowledge, they had problems adhering to these recommendations on a daily basis. In our study, patients were asked to chose between 33 products or methods of meal preparation and decide whether products were healthy to be eaten: "I can eat", or unhealthy: "It's forbidden to eat". On average respondents could decide on 17 from 33 given products (Figure 3 ).

Although recently the role of the diet in pancreatitis has increased, patients' knowledge remains on the same unsatisfactory level. There are a few factors that can be responsible for this situation. First of all, patients often pay too little attention to nutritional advice. On the other hand, in Poland, there are a limited number of dieticians employed in hospitals. Private nutritional advice can be too expensive for many patients. Nevertheless, it is important to increase patients' interest in nutrition and to increase their awareness of possible complications that can appear in the course of disease if such a diet is not implemented.

\section{Conclusions}

The results of the present study demonstrate that dietary knowledge among patients suffering from acute and chronic pancreatitis is insufficient. Although patients have theoretical knowledge about nutritional management, they have problems implementing the diet on a daily basis. Doctors and other health employers are indicated by patients as the main source of nutritional information; however, half of patients cannot fully understand their advice. Most (97\%) patients with acute and chronic pancreatitis adhere to the diet to various degrees, but almost $50 \%$ of people up to 35 years of age declared that they did not respect the diet, or followed only a few recommendations. The major reasons are lack of time for preparation, irregular meals, and lack of strong will to maintain the diet.

It is necessary to pay more attention to nutritional education for patients suffering from pancreatitis. This goal could be achieved by improvement of communication between health care employers and patients. More dieticians should be involved in the process of patients' nutritional education.

\section{Conflict of interest}

The authors declare no conflict of interest.

\section{References}

1. O'Reilly DA, Kingsnorth AN. A brief history of pancreatitis. J R Soc Med 2001; 94: 130-2.

2. Jarosz M, Dzieniszewski J. Choroby trzustki - porady lekarzy i dietetyków. PZWL, Warsaw 2009,

3. Kozieł D, Kozłowska M, Deneka J, et al. Retrospective analysis of clinical problems concerning acute pancreatitis in one treatment center. Prz Gastroenterol 2013; 8: 320-6.

4. Rydzewska G. Wybrane aspekty żywienia dojelitowego i pozajelitowego u dorosłych. Ped Współ Gastroenterol Hepatol Żyw Dz 2004; 6: 461-5. 
5. Heinrich S, Schäfer M, Rousson V, Clavien P. Evidence-based treatment of acute pancreatitis. A look at established paradigms. Ann Surg 2006; 243: 154-68.

6. Marik P, Zaloga G. Meta-analysis of parenteral nutrition versus enteral nutrition in patients with acute pancreatitis. BMJ 2004; 328: 1407-10.

7. Barra E, Socha J, Teisseyre M. Zaburzenia trawienia tłuszczów u dzieci z mukowiscydozą i przewlekłym zapaleniem trzustki. Ped Współcz Gastroenterol Hepatol Żyw Dz 1999; 1: 165-7.

8. Gąsiorowska A, Małecka-Panas E. Diagnostyka i leczenie przewlekłego zapalenia trzustki. Przew Lek 2007; 1: 76-86.

9. Kosel J, Kościuczuk U, Siemiątkowski A. The effect of nutritional treatment on immune function. Prz Gastroenterol 2013; 8: 147-55.

10. Haritha J, Wilcox CM. Evaluation of patients' knowledge regarding smoking and chronic pancreatitis: a pilot study. Gastroenterol Pancreatol Liver Disord 2015; 1: 1-4.

11. Majewski E, Kitlas J, Skotnicka-Graca U. Wiedza na temat diety w samoocenie pacjentów z chorobami przewodu pokarmowego. Ann Acad Med Siles 2005; 59: 354-8.

Received: 13.11.2014

Accepted: 21.01.2015 